\title{
Numerical modeling of ventilation and air conditions systems of large sport and culture centres
}

\author{
Michail A. Kolosov (a), Kirill S. Egorov ${ }^{\text {(a), }}$ \\ Bronislav B. Novitskiy ${ }^{\text {(a) }}$, Nikolay $S$. Malastowski ${ }^{(a)}$, \\ Larisa $V$. Stepanova ${ }^{(a)}$ \\ (a) Bauman Moscow State Technical University \\ Moscow, 105005, Russia, egorovks@bmstu.ru
}

\begin{abstract}
One of the most promising applications of highly effective computer technology (supercomputers) is numerical simulation of complex physical and thermophysical proccesses occuring in vast areas of concert halls and sport arenas while heating, ventilating and air conditioning. According to Russian technical standarts for building construction, numerical modeling of these systems should be carried out on the stage of their design. The variety of problems and demands, lack of understanding of the physical process involved and the necessity to make genuine decisions are encountered while conducting such a work. The experience in modeling of ventilation and air conditioning systems of Bolshoi Krenlevskyi Palace concert halls and the Moscow Conservatory named after P.I. Chaikovskyi, Zaryadie Park Philarmony concert hall and a covered ice rink arena is described. Keywords: Heat transfer, numerical modeling, ventilation system, design, concert hall

\section{INTRODUCTION}

Great attention is being paid to the conditions for spectators and athletes when considering a modern sports complex or a civic centers design [1,2]. According to the Russian Federation standards, comfortable conditions are as follows: ambient air temperature is about $23 \ldots 25^{\circ} \mathrm{C}$, its velocity is up to $0.3 \mathrm{~m} / \mathrm{s}$ (desirably about $0.2 \mathrm{~m} / \mathrm{s}$ ). The local temperature difference of the comfort zone height (i.e. the range of 0.1 to $1.5 \mathrm{~m}$ ), should not be more than $3^{\circ} \mathrm{C}$, and air velocity change should not exceed $0.1 \mathrm{~m} / \mathrm{s}(50 \%)$.

This design procedure is rather challenging because of the complex configuration of the buildings, the differences in heating loads and ventilation system layout. This fact is reflected in the modern Russian building standart SP60.13330.12 "Heating, ventilation and air conditioning", which requires ensuring the specified parameters of the microclimate in residential, public, administrative and industrial buildings by means of mathematical modeling (GOST 30494-11).

Today computational fluid dynamic (CFD) methods have been widely applied for architecture engineering purposes [3-11]. Computation machines performance growth and an improved numerical algorithms make it possible to discretize solution in a large irregular domain without precision loss by 10 to 100 million elements.
\end{abstract}


Some researchers [12] experimentally showed the possibility of using numerical methods in the design of sports facilities. Although the CFD does not replace the measurements, it allows engineers to reduce the overall cost of design process significantly. Thus, it is clear that CFD-modeling could reduce duration of the work and increase the quality of ventilation and conditioning processes according to the modern standards $[12,13]$.

As for stadiums, there are at least two areas of research, one for indoor spaces [6-10] and another for open spaces [3-5]. In the same time those places could contain specific features which could significantly influence the calculation procedure. Some authors carried out investigations for hockey rinks [6-8], swimming pools [10], and even a theatre located in the tropical zone [9].

In this paper the application of CFD calculations during the construction of some concert halls and a civic center's ice rink hall is shown. The coupling between air movement, heat transfer through the building frame, heat and mass transfer between the air and ice surface and water vapour dispersion make it necessary to use in all this cases the modern numerical methods of modeling. Software package ANSYS-CFX was used as an instrument.

\section{Methods and model}

The Eulerian-Eulerian model consisting of two species (air and water vapor) was used for present simulation. The volume fractions were distinct. For our case an inhomogeneous velocity fields coupled with homogeneous temperature field and in the same time all phases share the same pressure [14]. Equations describing turbulence model and boundary conditions complemented this system [8].

Continuity equation:

$$
\frac{\partial r_{\alpha} \rho U_{j}}{\partial x_{j}}=0 .
$$

Momentum equations:

$$
\frac{\partial \rho U_{i} U_{j}}{\partial x_{j}}=-\frac{\partial P}{\partial x_{i}}+\frac{\partial}{\partial x_{j}}\left[\left(\mu+\mu_{t}\right)\left(\frac{\partial U_{i}}{\partial x_{j}}+\frac{\partial U_{j}}{\partial x_{i}}-\frac{2}{3} \frac{\partial U_{k}}{\partial x_{k}} \delta_{i j}\right)-\frac{2}{3} \rho k \delta_{i j}\right]+g_{i} \rho \text {. }
$$

Energy equations:

$$
\frac{\partial \rho U_{j} T}{\partial x_{j}}=\frac{\partial}{\partial x_{j}}\left(\mu+\frac{\mu_{t}}{\sigma_{t}}\right) \frac{\partial T}{\partial x_{j}} .
$$

Turbulence is modelled with the shear stress transport (SST) model [15] This turbulence model uses a blending function to combine advantages of the $k-\varepsilon$ in the free stream region and the $k-\omega$ models in the near-wall region. The turbulent eddy viscosity is computed from the turbulent kinetic energy and turbulent frequency $\omega$ :

$$
\mu_{t}=\rho \frac{k}{\omega} .
$$


In our case the density variation is driven only by temperature variations, consequently the Boussinesq model is completely enough for calculations. A constant reference density is used for all terms other than the buoyancy source term. The buoyancy source term is approximated as:

$$
\rho-\rho_{\text {ref }}=-\rho_{\text {ref }} \beta\left(T-T_{\text {ref }}\right)
$$

where $\beta$ is the thermal expansivity:

$$
\beta=\left.\frac{1}{\rho} \frac{\partial \rho}{\partial T}\right|_{p} .
$$

Relative humidity is a measure of the amount of water contained in the air, defined by the ratio between the actual pressure of water vapor in the atmosphere and the pressure of saturated water vapor in the atmosphere at the same temperature, $\%$ :

$$
H R=\left(\frac{p_{v}}{p_{v s}}\right) \cdot 100 .
$$

The empirical relationship between the saturation vapor pressure and the temperature is given by the following equation [16] according to IAPWS IF 97 standart:

$$
\begin{aligned}
p_{v s}= & p_{c} \cdot \exp \left[\frac{T_{c}}{T} \cdot\left(a_{1}+a_{2} \cdot \tau^{1.5}+a_{3} \cdot \tau^{3.0}+a_{4} \cdot \tau^{3.5}+a_{5} \cdot \tau^{4}+a_{6} \cdot \tau^{7.5}\right)\right] \\
& \text { where }{ }^{\tau=1-\left(T / T_{c}\right)} .
\end{aligned}
$$

The estimated convective heat transfer coefficient from ice to air can be calculated as follows $[17,18]$ :

$$
h=3.14+3.55 \cdot V_{\text {air }} .
$$

\section{Results and discussion}

On the balcony of the Zaryadie Park Philharmony concert hall the location scheme of air blowing diffusers in the steps was considered. The results of velocity and temperature fields modelling with air supply of $43 \mathrm{~m}^{3} / \mathrm{h}$ per one spectator and their heat release of $72 \mathrm{~W}$ are shown in Fig.1, 2. As one can see from the results obtained on the last row the level of comfort is not acceptable (the speed exceeds $0.3 \mathrm{~m} / \mathrm{s}$, temperature is more than $+25^{\circ} \mathrm{C}$ ). Afterwards it was decided to supply additional air into the last step (Fig. 3, 4). Now we can see that the comfort conditions are almost achieved. 


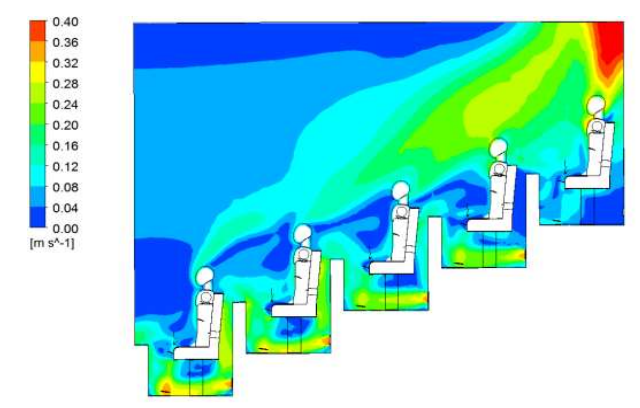

Figure 1. Location of diffusers supplying air and speed distribution as scalars on the balcony, $\mathrm{m} / \mathrm{s}$

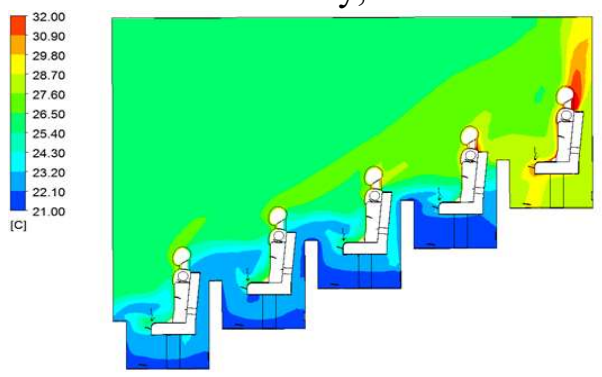

Figure 2. Temperature distribution on the balcony, ${ }^{\circ} \mathrm{C}$

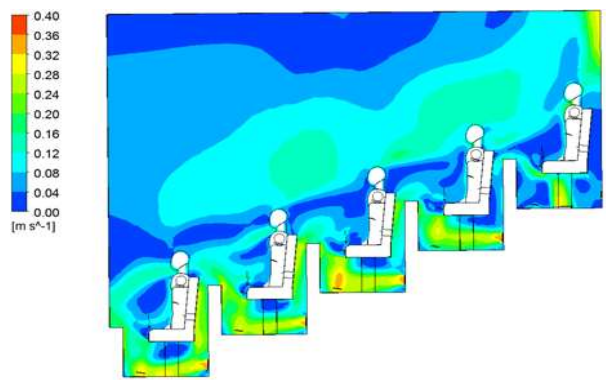

Figure 3. Location of air supplying diffusers and velocity distribution as scalars on the balcony in the presence of an additional diffuser, $\mathrm{m} / \mathrm{s}$

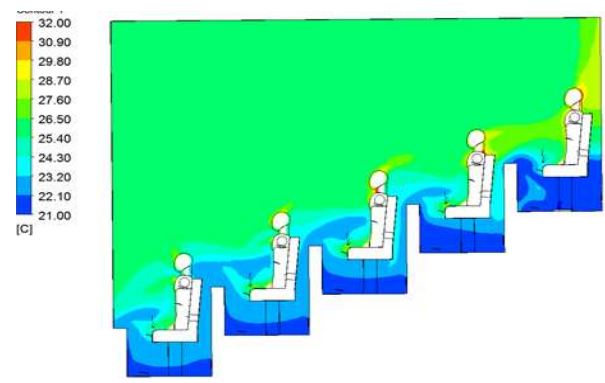

Figure 4. Temperature distribution on the balcony in the presence of an additional diffuser, ${ }^{\circ} \mathrm{C}$ 
Mathematical modeling in the total volume of the hall also makes it possible to identify problems with the supply or suction of air, as well as areas where comfort conditions have been violated for the audience or artists in general. It should be noted that the models are quite complex and they have to be refined from architectural ones using three-dimensional geometric modeling programs (for example, CATIA). Figure 5 show examples of some geometric models of Moscow Conservatory named after P.I. Tchaikovsky halls.

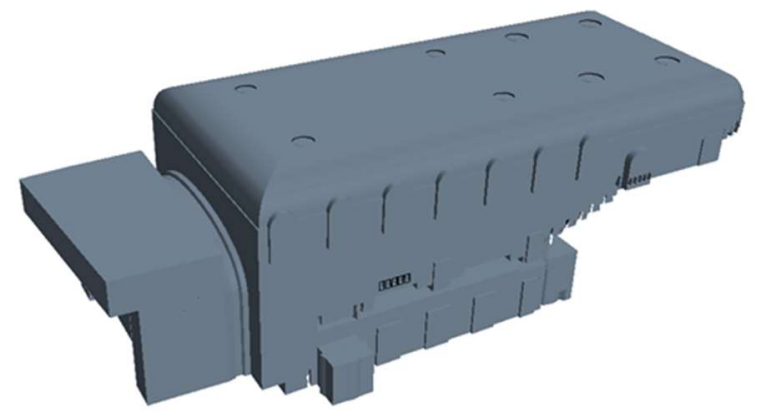

Figure 5. The appearance of the geometric model of the large hall of the Moscow Conservatory

Large models easily identify problems with air supply. Figure 6 shows the velocity field in the hall of the Moscow Conservatory in a vertical section along the center of the hall, which shows that a powerful air flow with a speed of more than $0.5 \mathrm{~m} / \mathrm{s}$ comes from the stage to the auditorium (stalls). There were some vortex areas [19-23] near the ceiling but there are no spectators there. On the basis of the conducted simulation, in order to eliminate the effect of air supply on the stage to the spectators on the ground, it was decided to reduce the air flow and install ventilation grids instead of nozzles. Figure 7 shows the velocity field with gratings on the stage. As you can see, the situation has improved significantly and the speed in the stalls does not exceed $0.5 \mathrm{~m} / \mathrm{s}$.

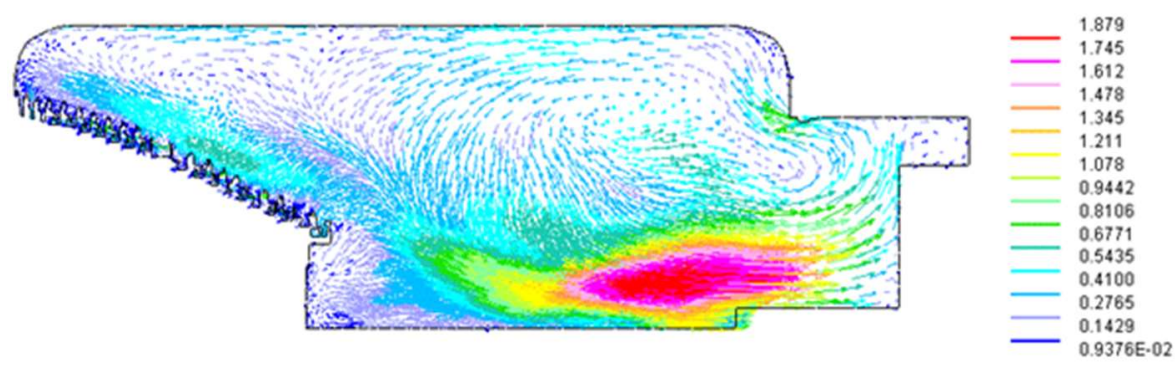

Figure 6. Air velocity field $(\mathrm{m} / \mathrm{s})$ in the stalls with nozzles on the stage 


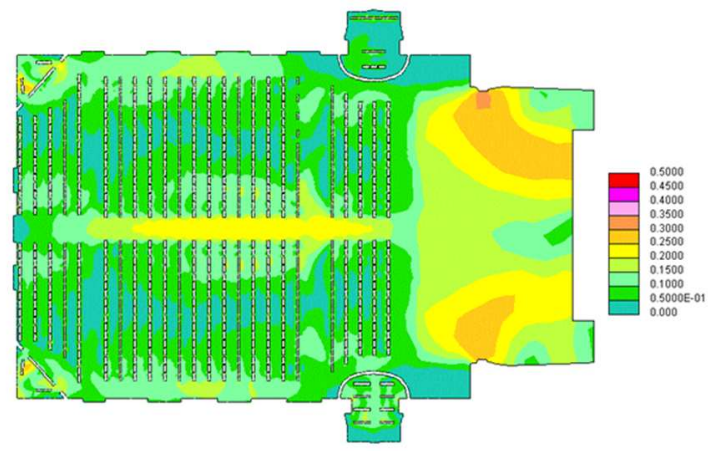

Figure 7. Air velocity field $(\mathrm{m} / \mathrm{s})$ in the stalls with bars on the stage

\section{CONCLUSIONS}

We have carried out many numerical simulations of ventilation and conditioning systems for different in-door sport facilities and city halls. Our experience shows that these stimulations are very helpful as they reveal problematic areas as early as on the stage of preliminary design; thus, they can be eliminated.

The modeling results showed that equation (Eq. 9), which is used for ice thermal emissivity prediction [17] gives very overrated values of heat exchange coefficient (5-6 times higher). Formula for free convection gives better approximation, e.g. [24]. Thermal emissivity coefficient overrun results in choosing excessive powered cooling equipment.

The results obtained also made it possible to validate the technique of ventilation and conditioning system prediction proposed in paper [1] and to calculate temperature and humidity values ( 0.92 and 0.91 respectively). It is especially essential for humidity value because it does not have reliable data. It is seen that our results correspond to those predicted by professor Kokorin's technique [1] for mixed ventilation scheme. Temperature value and humidity value are close to 1.0 in this case.

\section{NOMENCLATURE}

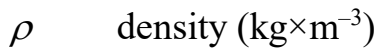

$\varepsilon \quad$ Kinetic energy dissipation, ()

$U, \quad$ velocity $\left(\mathrm{m} \times \mathrm{s}^{-1}\right)$

$\omega \quad$ turbulent frequency $(\mathrm{Hz})$

$x \quad$ Cartesian coordinate $(\mathrm{m})$

$\rho_{\text {ref }}$ buoyancy reference density $(\mathrm{kg} \times \mathrm{m}$

$i, j, \quad$ direction

$P, p \quad$ pressure $(\mathrm{Pa})$

$\mu \quad$ viscosity (Pa.s)

$T_{\text {ref }} \quad$ buoyancy reference temperature (K)

$\mu_{t} \quad$ turbulent viscosity, (Pa.s)

$\beta \quad$ thermal expansivity, $\left(\mathrm{K}^{-1}\right)$

$\delta_{i j} \quad$ Kronecker delta

$H R$ relative humidity $(\%)$

$p_{v} \quad$ pressure of water vapor $(\mathrm{Pa})$

$k \quad$ kinetic energy, $\left(\mathrm{J} \times \mathrm{kg}^{-1}\right)$

$p_{\text {vs }}$ pressure of saturated water vapor (Pa)

$p_{c} \quad$ the critical pressure of water vapour 


\begin{tabular}{|c|c|c|c|}
\hline$g_{i}$ & $\begin{array}{l}\text { acceleration of gravity } \\
\left(\mathrm{m} \times \mathrm{s}^{-2}\right)\end{array}$ & $T_{c}$ & $\begin{array}{l}(\mathrm{Pa}) \\
\text { the critical temperature of water } \\
\text { vapor }(\mathrm{K})\end{array}$ \\
\hline$T$ & temperature $(\mathrm{K})$ & $\tau, a_{i}$ & coefficients \\
\hline$\sigma_{t}$ & turbulent Schmidt number & $h$ & $\begin{array}{l}\text { convective heat transfer coefficient } \\
\left(\mathrm{W} \times \mathrm{m}^{-2} \times \mathrm{K}^{-1}\right)\end{array}$ \\
\hline
\end{tabular}

\section{REFERENCES}

1. O.Y. Kokorin, M.A. Kolosov, K.S. Egorov, AVOK Vent., otopleniye, konditsionirovaniye vozdukha, teplosnabz. i stroit. teplofiz., 2 (2013)

2. M.A. Kolosov, K.S. Egorov, Kholodil'naya tekhnika, 8 (2012)

3. G. Caruso, L. Santoli, M. Mariotti, Ventilation Design in Large Enclosures for Sports Events using CFD: the Halls of the "Città dello Sport" in Rome (2019)

4. A.I. Stamou, I. Katsiris, A. Schaelin, Appl. Therm. Eng., 28 (2008)

5. T. van Hooff, B. Blocken, J. Wind Eng. Ind. Aerodyn. (2012) https://doi.org/https://doi.org/10.1016/j.jweia.2012.02.009

6. . A. Palmowska, B. Lipska, Int. J. Refrig., 86 (2017) https://doi.org/10.1016/j.ijrefrig.2017.11.016

7. S. Lestinen, T. Laine, T. Sundman, Scoring an HVAC global for hockey spectators. CFD is used to design ventilation systems for sports arenas. ANSYS Adventage I/1 (2007)

8. A. Palmowska, B. Lipska, Build. Environ., 108 (2016)

9. Y. Cheng, J. Niu, N. Gao, Energy Build., 55 (2012) https://doi.org/10.1016/j.enbuild.2012.09.021

10. K.W.D. Cheong, E. Djunaedy, Y.L. Chua, K. Tham, C. Sekhar, N.H. Wong, M.B. Ullah Build. Environ., 38 (2003) https://doi.org/10.1016/S0360-1323(02)00020-3

11. P. Ciuman, B. Lipska, Build. Environ., 145 (2018) https://doi.org/10.1016/j.buildenv.2018.09.009

12. I.A. Burkov, A.V. Pushkarev, A.V. Shakurov, D.I. Tsiganov, A.A. Zherdev, Int. J. of Heat and Mass Transf. 147, №1 18946 (2020)

13. S.E. Lauk-Dubitskiy, A.V. Pushkarev, I.A. Korovin, A.V. Shakurov, I.A. Burkov, L.O. Severgina, A.A. Zherdev, D.I. Tsiganov, I.A. Novikov, Cryobiology, 93 (2020)

14. E. Antonova, Determination of parameters of the water-air mixture generated by an ejection aeration system with a dispersing agent. IOP Conf. Ser. Mater. Sci. Eng. 492, 12027 (2019) https://doi.org/10.1088/1757-899X/492/1/012027 
15. .F.R. Menter, Two-Equation Eddy-Viscosity Transport Turbulence Model for Engineering Applications. AIAA Journal 32, 8 (1994). https://doi.org/10.2514/3.12149

16. W. Wagner, A. Pruss, J. Phys. Chem. Ref. Data 22 (1993) https://doi.org/10.1063/1.555926

17. M.S. Owen, ASHRAE Handbook, Refrigeration (2010)

18. G. Goncharova, T. Ustugova, I. Nikiforova, N. Razomasov (Proc. 24th IIR Int. Congress of Refrigeration, Yokohama, 2015)

19. A.Y. Varaksin, M.A. Orlov, Dokl. Phys., 63 (2018) https://doi.org/10.1134/S1028335818090070

20. A.Y. Varaksin, M. V. Protasov High Temp. 55 (2017) https://doi.org/10.1134/S0018151X17060177

21. A.Y. Varaksin, Air tornado-like vortices: Mathematical modeling (a review), High Temp.,55 (2017) https://doi.org/10.1134/S0018151X17020201

22. P. Dermer, A. Varaksin, A.I. Leontiev, Int. J. Heat Mass Transf., 110 (2017) https://doi.org/10.1016/j.ijheatmasstransfer.2017.03.076

23. A.Y. Varaksin, Concentrated air and fire vortices: Physical modeling (a Review), High Temp., 54 (2016) https://doi.org/10.1134/S0018151X16030226

24. W. Maake, J.-L. Cauchepin, H.-J. Eckert, Le Pohlmann (1993) 